\title{
A Study on artificial lighting source using X3D
}

\author{
Gyung-Bae Park*, Kyung-In Kang ** \\ X3D를 이용한 인공조명에 관한 연구
}

박 경 배*, 강 경 인 **

\begin{abstract}
An artificial light source has a character that a light emits from a point to all directions with many radial and straight ray shapes. It is very difficult and complex to render those emitting lights. Also, users have difficulty in expressing exactly 3D objects because of colors varying with changing of a light and having many parameters. In this paper, to solve those problems we design an artificial light source using X3D to create a model that represents easily many radial and straight ray shapes and propose the online system that each factors of colors to be reflected by a light is separated and then users can control them to detect object's colors by a mouse. Various light sources with reality can be easily created using proposed system.
\end{abstract}

\section{요 약}

인공조명의 특징은 중앙을 기준으로 수많은 방사형과 직선형 빛을 방출한다. 이러한 빛의 퍼짐을 $3 \mathrm{D}$ 로 표현하기 는 매우 어렵고 복잡하다. 또한 빛의 효과에 따른 물체의 색상은 매우 다양하고 많은 변수 값 때문에 사용자가 정확 히 물체를 표현하기 어렵다. 이러한 문제점을 해결하기 위하여 본 논문에서는 방사형과 직선형 빛을 손쉽게 표현하 기 위한 모델을 제시하고 $\mathrm{X} 3 \mathrm{D}$ 를 사용하여 인공조명을 설계하였다. 그리고 사용자가 $3 \mathrm{D}$ 물체의 색상을 정확하고 쉽 게 표현할 수 있도록 물체의 색상을 요소별로 분리한 후 사용자가 직접 육안으로 각 요소의 색상 값을 관찰하며 조 정하도록 온라인 시스템을 제안하였다. 제안된 시스템을 사용하여 다양한 인공조명을 손쉽게 생성할 수 있었다.

- Keyword : 3D computer graphic, X3D, lighting model, SpotLight

- 제1저자 : 박경배

• 투고일 : 2010. 01. 18, 심사일 : 2010. 02. 11, 게재확정일 : 2010. 03. 11.

* 여주대학 인터넷정보처리과 부교수 $* *$ 여주대학 정보통신과 부교수 


\section{Introduction}

There are a source of light and three lighting model in 3D computer graphics like X3D and OpenGL[1][2]. A source of light is a headlight like sun in the real world. It is a directional light that always points in the direction the user is looking. Setting a source of light field to FALSE disappears a headlight and a user doesn't see anything. But if it has a TRUE, Because a light has the characters a diffuse and specular reflection on a surface of geometric objects, all objects in the scene are showed like 3D by light's effects. Therefore, each geometric objects in 3D graphics will be considered the light's character.

For specifying the visual properties of geometry, first of all its material must be determined. The properties of material determine how light reflects off an object's surface to create colors. The colors of an object are composed three main factors which are emissive, diffuse and specular of the light and three extra factors which are ambient, shininess and transparency. Also each main factors is composed of colors with red, green, blue[3]. Each of them is applied to lighting equation during rendering. In its range from 0.0 and 1.0, a user will determine oneself the object's colors. But it has a difficulty that a user makes exactly to predict finished the colors of an object. There are too many factors and they have a wide range in color value. Because of these reasons, most of graphic editors like vrmlpad[4] use a keyboard for the color edition of a object. Even those editors, a user directly types his wanted values, and in that too, it's difficult to find exact colors.

When a light rendered considering is Off, the other three lighting model that is DirectionalLight, PointLight, SpotLight will be used[5]. They are similar a light source except that a user can define color and position of a light. Specially, the SpotLight specifies a light source that emits light from a specific point along a specific direction vector and constrained within a solid angle. But all these lighting models express only influence of light on the objects and not themselves. In a dark scene, as an illumination of light expresses a dramatic effect, it's a very important to display a lighting source itself. But to render the area of a light emitted is very difficult and complex.

In this paper, to solve those problems we propose the online system that each factors of a color to be influenced by a light will be separated and users can control them to determine colors by a mouse. To interface with mouse is a benefit that a user directly examines colors varying with changing of each factor's value. So the user can exactly and easily determine the colors of the objects. Also we make geometry convex model for the area of a light emitted and apply this system model to the property of SpotLight, various light sources with reality can be created easily.

Chapter II describes about the mechanism of lighting model and the colors of an object. Also, we consider that what need to display a lighting source. In chapter III, we discuss our detecting color model by a mouse and explain how to design. We give simple illustration of our performance evaluation and analysis in chapter IV and conclude our research in chapter $\mathrm{V}$.

\section{Lighting model}

\section{Light rays and colors}

Light is a most important component behind visual representation 3D objects that a user can visually perceive. Fig. 1 shows the relation of a light source and the colors of an object and three different types of light[6]. Even if same object is differently showed as the position of light rays. If a light source is located on the right of an object, the right surface of the object is reflected by the light.

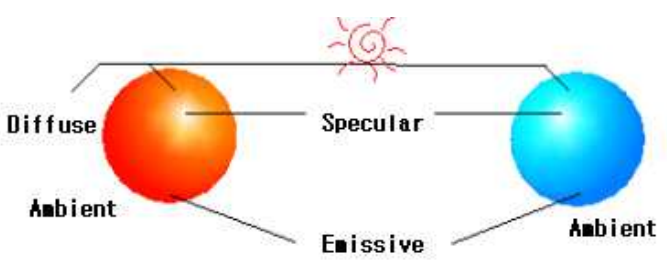

Fig. $1 \mathrm{~A}$ light source and the colors of a object

Emissive light component is responsible for the material's property of an object to absorb light. That is, it models glowing entire objects. If a light source is ' $\mathrm{OFF}^{\prime}$, only the 
emissive color will be showed. Diffuse light reflects light sources depending on the angle of the surface with respect to a light source. The more directly the surface faces the light, the more diffuse light reflects. Specular light reflects off the surface in a sharp and uniform way. The rendering of specular light relies on the angle between the viewer and the light source. It depends on the diffuse light and shininess of which lower values produce soft specular while greater values result shaper, smaller specular right. So specular light and shininess seems to be a important component to make a new lighting model. In addition to this, ambient light specifies how much ambient light from light sources this surface shall reflect. Transparency specifies how clear an object is, with 1.0 being completely transparent, and 0.0 completely opaque.

\section{Lighting equations}

Emissive, Diffuse and Specular light are consist of $\mathrm{R}$ (red), G(green), B(blue) in range from 0.0 to 1.0 each. Table 1 shows the finished color of 3D object and base on evaluation the following lighting equation on each point a lit surface[7][8].

Table 1. The relation of emissive, diffuse and specular

\begin{tabular}{|c|c|c|c|}
\hline Factor & r,g,b & Applied area & Finished color \\
\hline emissive & $1,0,0$ & entire & 100 \\
\hline diffuse & $0,1,0$ & a part of surface & $100+010=110$ \\
\hline specular & $0,0,1$ & shiny spots & $100+010+001=111$ \\
\hline
\end{tabular}

$\mathrm{Irgb}=\mathrm{OErgb}+\mathrm{SUM}($ oni $\times$ attenuationi $\times$ spoti $\times \mathbb{L r g b} \times$ (ambienti + diffusei + speculari $))$

where :

OErgb = Emissive Color

Oni $=1$ or 0 , as light source affects this point

attenuationi $=1 / \max \left(\mathrm{cl}+\mathrm{c} 2 \times \mathrm{dL}+\mathrm{c} 3 \times \mathrm{dL}^{2}, 1\right)---(2)$

$\mathrm{c} 1, \mathrm{c} 2, \mathrm{c} 3=$ light $\mathrm{i}$ attenuation

spoti $=$ spot light factor $($ Table 2$)$

ILrgb = light i Color

Ii $=$ light $\mathrm{i}$ intensity

ambienti $=$ diffuse $\times$ light $\mathrm{i}$ ambient $\times$ ambient

diffusei $=\mathrm{Ii} \times$ diffuse $\times \mathrm{N} \cdot \mathrm{L}$

speculari $=$
Ii $\times$ OSrgb $\times(\mathrm{N} \cdot((\mathrm{L}+\mathrm{V}) / \mathrm{L}+\mathrm{V} \mid))$ shininess $\times 128 \quad---(3)$

OSrgb = Material specularColor

$\mathrm{N}=$ normalized normal vector

$\mathrm{L}=$ (Point/SpotLight) normalized vector

$\mathrm{V}=$ normalized vector to viewer's position

In equation (1) and Table 1, Irgb means RGB intensity at each point on a geometry. OErgb affects diffuse and specular component and weigh with Irgb. If OErgb has a value, diffuse color carries out OR operation with OErgb. Similarly with diffuse component, specular color carries out OR operation with OErgb and diffuse color. Notice that Irgb is light color. Unlike material color, light color and object color carry out not OR but AND operation. If ILrgb has not (1,1,1), a object's colors will be showed differently.

In visual representation, speculari and spoti are important factors. In equation (3), speculari will be calculated OSrgb and normal vector raised to the shininess $\times 128$ power. Shininess is the second feature of the specular light and not a lit by itself. If shininess factor values 128 , the specular reflection is very bright with white spot which appears on objects with materials of high reflectivity. As there are too many factors to determine of Irgb, a user will feel a difficulty.

In the next 2.3 section, We will discuss spoti that is a component of SportLight which is used us to make a light source.

\section{The Character of SpotLight}

As shown In Fig. 2, the SpotLight defines a light source that emits light from a specific point along a specific direction vector and constrained within a solid angle.[9]

The radius defines the radial extend of the solid angle and the maximum distance from location that may be illuminated by the light source. The beamwidth specifies an inner solid angle in which a light source emits light at uniform full intensity. The cufOffAngle specifies the outer bound of the solid angle. SpotLight illumination fall off with distance by attenuation, as in equation (2). Irgb which is affected by the SpotLight is determined as the result of calculation spoti factor in Table 2. 


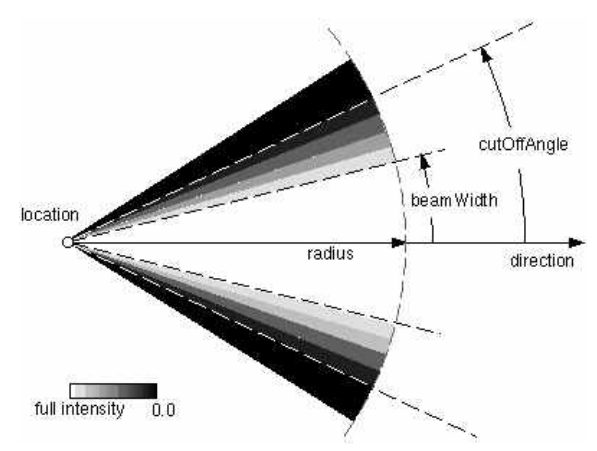

Fig.2 The character of SpotLight

Table 2 The condition of the SpotLight

\begin{tabular}{|c|c|}
\hline Condition & spot \\
\hline spotAngle $>=$ spotCO & 0 \\
\hline spotAngle $<=$ spotBW & 1 \\
\hline spotBW $<$ spotAngle<spotCO & $\begin{array}{c}\text { (spotAngle-spotCO) } \\
\text { (spotBW-spotCO) }\end{array}$ \\
\hline
\end{tabular}

where:

spotAngle $=\operatorname{acos}(-\mathrm{L} \cdot$ spotdirection $)$

spotBW $=$ SpotLight BeamWidth

spotCO $=$ SpotLight CutOffAngle

If a light source intensity drops off from the inner solid angle to the outer angle, spotAngle $(0 \leq$ spotAngle $\leq \pi)$ is located at between spotBW and spotCO. those the characters of Spotlight have a advantage in design a light source with reality. If we can realize the part from spotBw to spotCo as the area of light emitted, a user can directly render an artificial light source look-like a light source. We propose how to determine easily the color of objects and realize the area of a light emitted in next chapter III.

\section{Color and a light source model}

\section{An artificial light source Model}

As shown in Fig. 3, a light source has a character that a light emits from a point to all directions with many radial and straight ray shapes. These ray shapes are not easy to render artificially. But if SpotLight and a convex object are used, they can be rendered.

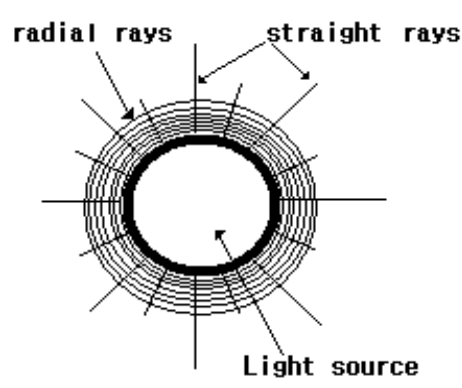

Fig. 3 Radial and straight rays of light source

If the condition of SpotAngle is spotBW $<$ spotAngle $<$ spotCO as in Table 2, the field cutOffAngle appears many radial shapes. Therefore spotCO must be greater than spotAngle and spotBW. In this condition, the intensity of Specular depends on shininess as in equation (3). For the straight shape of light, a convex object may be rendered by Extrusion node[15] which is based on a two dimensional( $\mathrm{y}=0$ ) cross section and extruded along a three dimensional spine.

First to render an artificial light source, the field crossSection of Extrusion node is defined $2 \mathrm{D}$ circle that is rendered with 16 points on $\mathrm{x}$ and $\mathrm{z}$-axis plane. And then scale value is controlled to be curved surface to the direction of

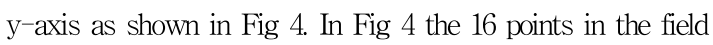
crossSection are modified largely by scale and spine and shaped straight lines in this process. If a light reflects off this object, those lines will be showed as straight rays. If radial ray shapes of SpotLight and straight ray shapes of the convex object are merged, an artificial light source can be rendered as shown in Fig. 4.

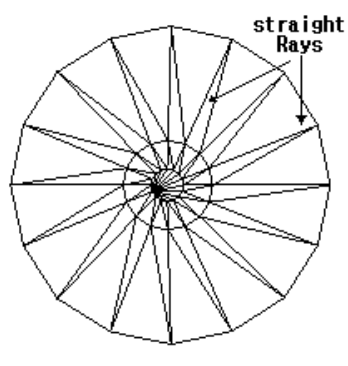

Front Convex

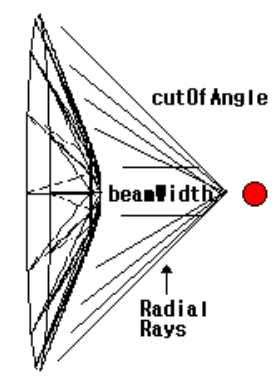

Side Convex
Fig. 4 Convex model and SpotLight 
If the artificial light source is applied to following the model detecting colors, artificial light sources with various color are rendered.

\section{Detecting color Model}

Already above mentioned in equation (2), Irgb has too many factors for determining RGB intensity at each point on the geometry. A user directly types each factor's value in range from 0.0 to 1.0 for Irgb. To typing directly factor's values, ranging from 0.0 to 1.0, it is troublesomeness as well as not precision. If the values are not precision, may be modified subsequently.

To solve this problem, input interface by a keyboard must be modified by a mouse. Using a mouse has the merits to reduce troublesomeness in typing directly and to predict the result of colors. If we can map a mouse displacement amount into each factors of Irgb, above mentioned problems is naturally solved.

Fortunately, In X3D, PlaneSensor[10] maps a mouse motion into $2 \mathrm{D}$ translation $(Z=0)$. we suggest a model detecting colors with interface object including PlaneSensor as shown in Fig 5.

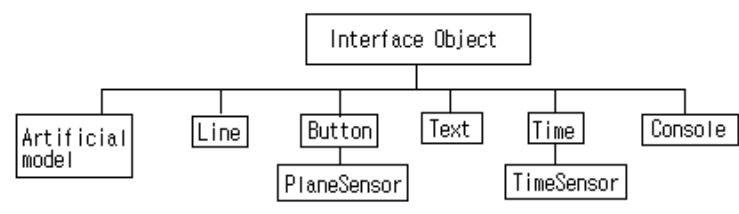

Fig 5. Interface object for detecting colors.

Artificial model object is an artificial light source introduced in Fig 4 and user can directly examines colors varying using that.

As shown in Table 3, Line and Button object are all 12 components having default in material(Irgb). A Line(size=1) object is guide line of a Button object. The moving of a Button which is controlled by mouse is delivered to each components and can not deviate from a Line. The initial place of a Button and the default are same position(diffuse $=0.8$. .

Each Button objects has a PlaneSensor object. The translation_changed field of PlaneSensor is output which corresponds to the sum of the relative translation from the original point to the next point. Because each components range is from 0.0 to 1.0 , minPosition and maxPostion of PlaneSesnor must be restricted to 0.0 and 1.0 each. PlaneSensor must be applied to every Buttons to move each Buttons by a mouse. Fig 6 . shows the flowchart displaying event processing as the Button's moving.

Table 3. The factor of color

\begin{tabular}{|c|c|c|}
\hline factor & component & default \\
\hline Emissive & red, green, blue & $0,0,0$ \\
\hline Diffuse & red, green, blue & $0.8,0.80 .8$ \\
\hline Specular & red, green, blue & $0,0,0$ \\
\hline ambient & intensity & 0 \\
\hline shininess & intensity & 0.2 \\
\hline transparency & intensity & 0 \\
\hline
\end{tabular}

To detect a mouse movement, change the scene and deliver the parameters, an event must be occurred and the values of the objects are modified by processing Route. Route is a construct for establishing event path between specified field of objects[11].

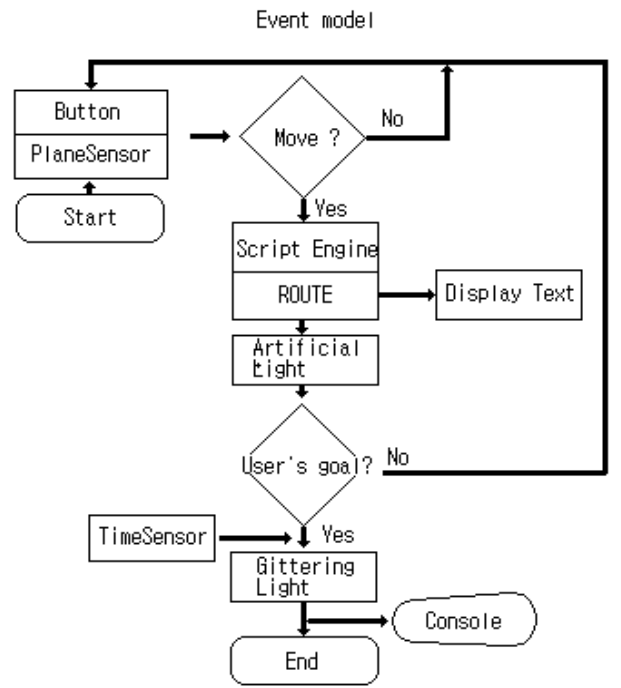

Fig 6. The flowchart for detecting color

But Route can be only used in same data type between source and destination. In case movement of 
mouse(SFVec3f) and changing color(SFColor), two data types are different. If they are different types, a program module that performs displacement computation is included in Script object[12].

Following Route statement is to modify Button's position and change the colors of an object according to mouse's movement. The changing value of Diffuse is displayed as text in Text object(text_r field).

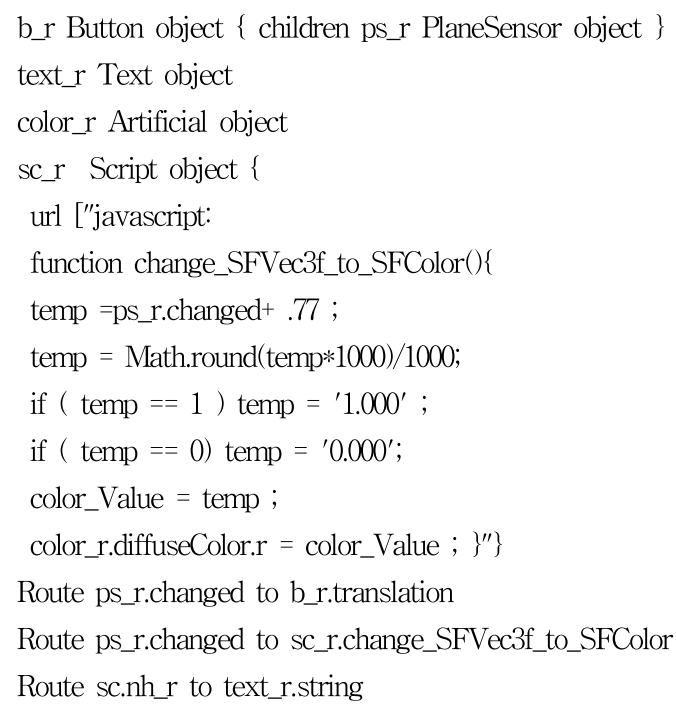

In the real world a light source has a feature glittering. This effect can be realized using Time object, shininess and Interpolators[13][14]. TimeSensor will generate events as time passes and execute in cycle. Interpolator dependent upon TimeSensor interpolates linearly among a list of key to produce key_value event. If the factor of a shininess is changed as time passes, an artificial light source will be glittering automatically like a light source in the real world.

Console object displays changed color's values to use the detect colors model for users. The users can use data for their object color values or artificial light source as copying them We will explain the proposed system and the evaluation result in chapter IV.

\section{Realization of proposed model}

Our detecting color and an artificial light source model was implemented on Window XP OS and programmed with X3D using X3D-Edit 3.1 editor. For modeling an arrificial light source, a SpotLight is used with beamWidth $=0.2$ and CutOfAngle $=0.66$, and the location of the SpotLight is over a distance of 2 from a convex object as shown in Fig. 4. As we service this program through our http server, the user wanted to use this system must install X3D viewer program in its client computer as shown Fig. 7.

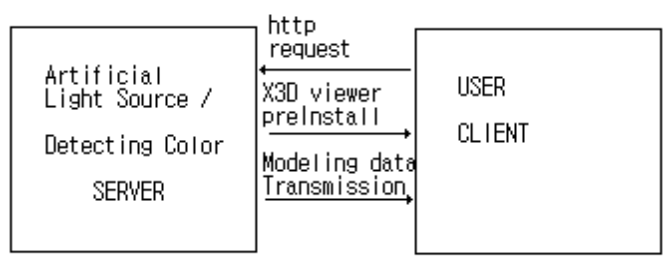

Fig. 7 Proposed on-line system

Fig. 8 shows the scene of the client connected to the modeling server. It is made up twelve Buttons for input interface, an artificial light source, Glitter\&Code text for glittering of the artificial light source and saving the code, console window for displaying the material field.

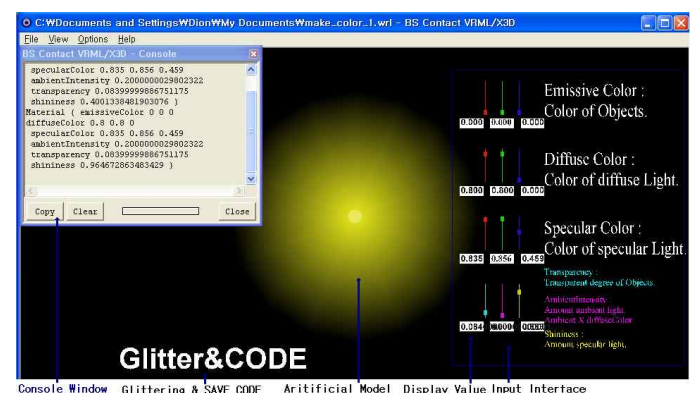

Fig. 8 The scene of the client connected to server.

Twelve Buttons controlled by a mouse are located in right panel and an artificial light source is located in left. The colors of an artificial light source will be changing according as moving a button among the twelve buttons. The Buttons to change the colors of Emissive, Diffuse and Specular are each disposed from top to down. Notice that initial values of the diffuse factors are 0.8 all. The lowest Buttons to change transparency, ambient and shininess of a 
light source are each located from left to right. The values of each factors to display current color values are located below of each Buttons.

As an example of application, the values of the artificial light source emitted yellow light is displayed by console as shown in Fig 9 and users can use this code to arrive their goal by copy.

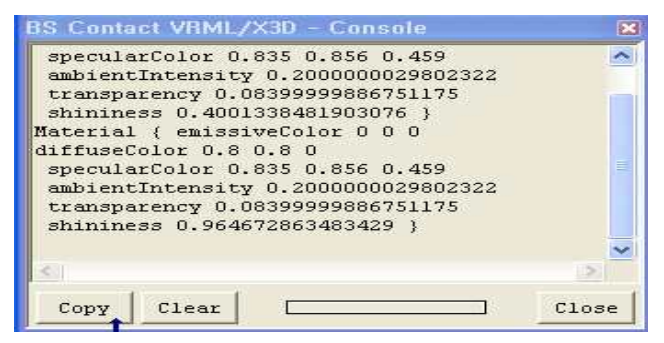

Fig. 9 Console window for displaying material field.

For evaluation about the detecting color, we try test that is how to affect visually an object with each factors. Emissive and Ambient seem not to affect artificial light source as shown Table 4. In order not to display the borderline of artificial light source, All components of Emissive that is itself color of an object have 0.0.

Table 4. The relation of the factor and artificial light source(AIS).

\begin{tabular}{|c|c|c|c|c|c|c|}
\hline factor & $\begin{array}{c}\text { emi } \\
\text { ssive }\end{array}$ & diffuse & specular & ambient & shininess & transparency \\
\hline Affection & $\mathrm{X}$ & $\mathrm{O}$ & $\mathrm{O}$ & $\mathrm{X}$ & 0 & 0 \\
\hline Emitted Area & - & Radial ray & Size & - & $\begin{array}{c}\text { Size, } \\
\text { Lightness }\end{array}$ & $\begin{array}{c}\text { Visual } \\
\text { effect }\end{array}$ \\
\hline
\end{tabular}

Diffuse corresponded with the area of a light emitted is displayed with different color according as the combination of each component. As shown in Fig. 8, yellowed lights are combination of red $=0.8$, green $=0.8$, blue $=0.0$. Remember that the area of artificial light emitted is made up radial and straight rays. Radial rays are more sensitive about the component of Diffuse. For example with $r=1, g=0, b=0$, if an artificial light source has only one component of Diffuse, the radial rays of the light source are displayed less than to be made up two more components. That is, to consist of two more components of Diffuse may be more displayed radial rays of the light source by the interference effect of the colors.

Specular is center of a light source. In order to naturally display a light source, it's component values may be same with the Diffuse components. Of course, they can be adopted slightly different values for something dramatic effects. They depend closely on shininess that is not a lit by itself. If shininess factor values 1 , The Specular is very bright with small spot. It's value has closer to 0 , it is displayed larger and weaker over Diffuse area. Fig. 10 shows that shininess factor of light source is $0,0.5$ and 1 each.

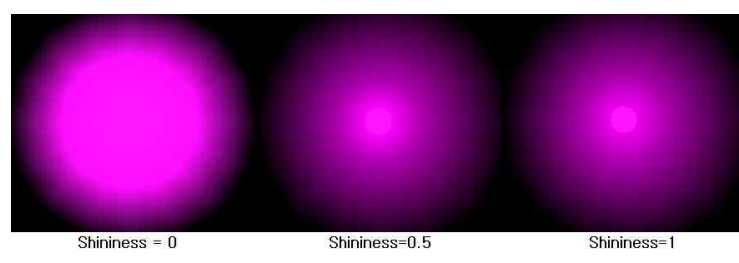

Fig. 10 A light source as shininess factor.

Fig. 11 shows the center size and brightness of the artificial light source according as the shininess value(each has unit 1). In our artificial modeling, Shininess of which lower values produce soft and larger specular light(size $=0.9$, brightness $=0.2$ ) while greater values result smaller and shaper specular (size $=0.1$, brightness $=1$ ) right.

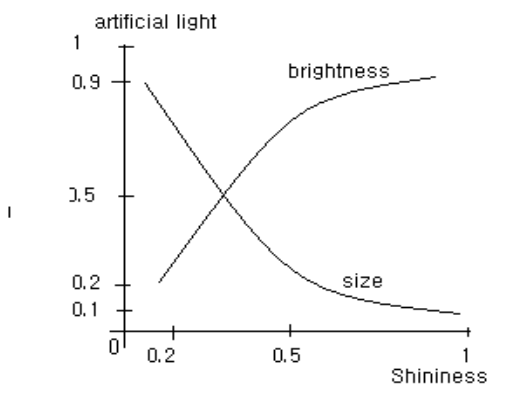

Fig. 11 The relation size and brightness according as the changing of the Shininess

Transparency component is secondary element to display the area emitted of artificial light source. But to select 
transparency component's value may be careful. Because transparency is transparent degree of an object, it has closer to 1 , the object gradually is not seen. We recommend it's range from 0.1 to 0.5 .

Fig. 12 shows that the source light is glittering as time passes with cycle 1 . Generally time cycle is less than 1 for the glittering of the artificial light source.

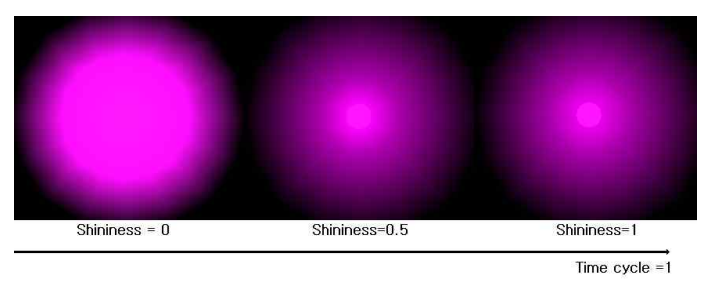

Fig. 12 The glittering effect as time passes.

\section{v. Conclusion}

We suggest and develop a system that detects colors of an object and models an artificial light source. For users want to know the color values of an object and to render an artificial light source, we service this system through our link site http://cafe.naver.com/vrmlx3d. This online system has the merits in field such as education and development to be concerned about the colour as the following.

1. A teacher explains easily the principle of which a color is illumination of a light and consists of red, green, blue.

2. As users directly practice the proposed online detecting color system, they can easily understand the character of a light to consist of emissive, diffuse and specular.

3. To control the color's values of 3D object by a mouse is very helpful to determine colors of an object very fast and easy.

4. A developer who designs game or scene of night can render easily and quickly an artificial light source and creates dramatic scenes.

We verify usefulness and efficiency of the detecting color and modeling artificial light source with realtime system And for more natural glittering of the artificial light source, more research is needed about the relation of the time cycle and various interpolators that interpolate linearly a list of key to produce key_value depended on time.

A later research, we think that other artificial light sources like LED(Light Emitted Device) or Neon sign can be developed using proposed modeling artificial light. These light sources use largely as advertisement sign in indoor or outdoor area. If those light sources are applied in 3D space, they are widely used in commercial purpose.

\section{Reference}

[1] Don Brutzman and Leonard Daly, "X3D: 3D Graphics for Web Authors," Morgan Kaufmann Publishers, 2006.

[2] "The OpenGL Graphics System: A Specification (Version 1.1)," Silicon Graphics, Inc., 1995.

[3] 박경배, “Web3d를 위한 $V R M L$ 실습과 응용," 21세기 출판 사, 129-133쪽, 2009.

[4] ParallelGraphics,-Web3D product, http://www.parallelgraphics.com/products/vrmlpad/ features/

[5] Web3D Consortium-X3D Document, http://www.web3d.org/X3d/specifications/vrml/ISO-IE C-14772-VRML97/part1/concepts.html\#4.6.6

[6] 박경배, 곽승욱, "Web3d 디자인을 위한 예제 중심의 X3D," 글로벌 출판사, 103-107쪽, 2008.

[7] 박경배, 유충열, “ $3 D$ 가상홈페이지 만들기," 21 세기 출판사, 2007.

[8] Foley, van Dam, Feiner and Hughes, "Computer Graphics Principles and Practice," 2nd Edition, Addison Wesley, Reading, MA, 1990.

[9] X3D, ISO/IEC 19775-1:2008, http://www.web3d.org/X3d/specifications/ISO-IEC19775-1.2-X3D-AbstractSpecification/Part01/component s/lighting.html\#SpotLight

[10] X3D, ISO/IEC 19775-1:2008, http://www.web3d.org/x3d/specifications/ISO-IEC19775-1.2-X3D-AbstractSpecification/Part01/compone nts/pointingsensor.html

[11] VRML97, ISO/IEC 14772-1:1997, http://www.web3d.org/x3d/specifications/ $\mathrm{rmml} / \mathrm{ISO}-$ IEC-14772-VRML97/part1/concepts.html\#4.10 
[12] X3D, ISO/IEC 19775-1:2008,

http://www.web3d.org/x3d/specifications/ISO-IEC19775-1.2-X3D-AbstractSpecification/Part01/compone nts/scripting.html

[13] X3D, ISO/IEC 19775-1:2008,

http://www.web3d.org/X3d/specifications/ISO-IEC19775-1.2-X3D-AbstractSpecification/Part01/compone nts/time.html

[14] X3D, ISO/IEC 19775-1:2008, http://www.web3d.org/X3d/specifications/ISO-IEC19775-1.2-X3D-AbstractSpecification/Part01/compone nts/interp.html

[15] X3D, ISO/IEC 19775-1:2008, http://www.web3d.org/x3d/specifications/ISO-IEC19775-1.2-X3D-AbstractSpecification/Part01/compone nts/geometry3D.html\#Extrusion

\section{저 자 소 개}

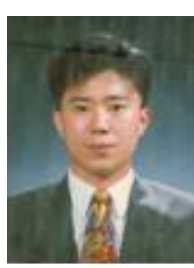

박 경 배

2001년 : 명지대학교 전자공학과 공학 박사

1998년 3월부터 현재까지 :

여주대 인터넷정보처리과 부교수

관심분야 : 이동통신, 네트워크

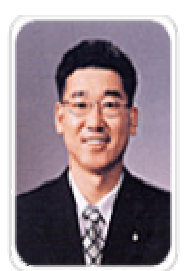

\section{강 경 인}

2001년 : 명지대학교 전자공학과 공학

$$
\text { 박사 }
$$

1998년 3월부터 현재까지 :

여주대 정보통신과 부교수

관심분야 : 이동통신, 네트워크 